\title{
Effect of Water on Ionic Conductivity of the Sintered Bodies of $\mathrm{CaF}_{2}$
}

By

\author{
Susumu MIZUTA, Seiichi ARAI and Hiroaki YANAGIDA \\ (Department of Industrial Chemistry, The University of Tokyo)
}

\section{Introduction}

Investigation into ionic conduction due to migration of fluorine ions in calcium fluoride has been performed using single crystals $^{1) \sim 57}$ as shown in Fig. $1(\mathrm{U}, \mathrm{P}, \mathrm{N})$. Ionic conduction in single crystals is generally explained as follows. In the low temperature region the ionic conduction is due to the migration of fluorine ions along dislocations or through frozen-in defects, while fluorine ions migrate through thermally produced fluorine ion vacancies or interstitials in the high temperature region. Previous investigators ${ }^{1 / 5)}$ have shown the values of the activation energy in the high temperature region and in the low tem. perature region, in the range of $1.60 \sim 2.00 \mathrm{eV}$

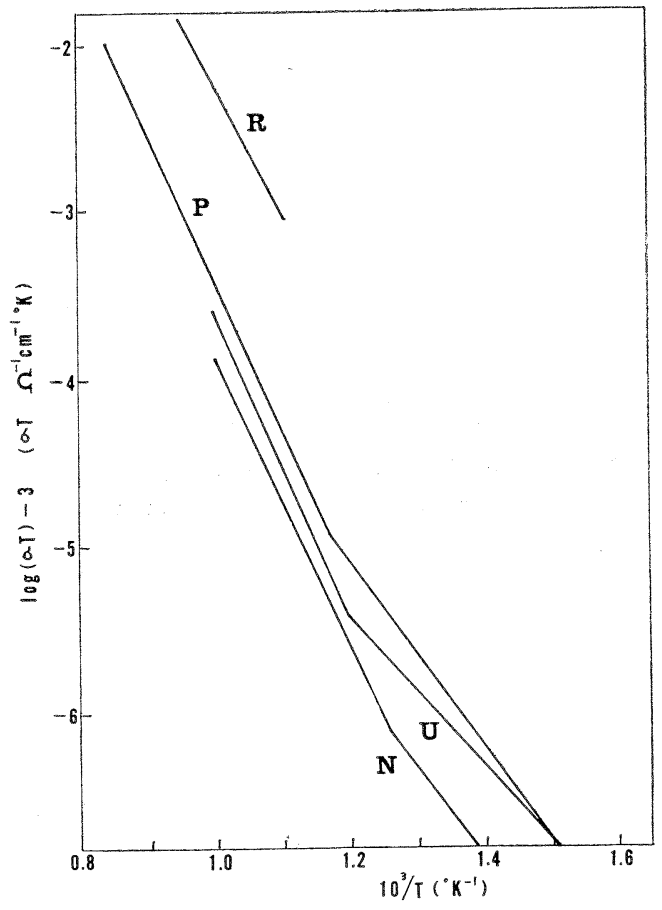

Fig. 1. $\log \sigma T$ vs. $1 / T$ in $\mathrm{CaF}_{2}$ single crystals, by Ure (U, Ref. 1), Popov (P, Ref. 3), Nikitinskaya (N, Ref. 4) and those in $\mathrm{O}^{2-}$ doped single crystal by Rossing (R, Ref. 7). and $0.75 \sim 1.10 \mathrm{eV}$ respectively.

No descriptions, however, have been given of electrical conduction in sintered bodies of calcium fluoride. The effects of grain boundaries to ionic conduction must be estimated in sintered bodies. It is generally thought that grain boundaries greatly increase ionic conductivity in an extrinsic region. Unfortunately it is not possible in most of the cases to define the contribution of grain boundaries to conduction unequivocally. Depending on grain growth, segregation of impurities or interaction with atmosphere, the properties of grain boundaries are sensitive to the condition of sintering.

Although it is undoubtedly desirable to analyze the properties of grain boundaries microscopically, it is hardly possible to look sight into the atomic order properties of grain boundaries in sintered bodies owing to technical difficulties. Present authors took macroscopic standpoint to discuss the properties of grain boundaries investigating the relation between electrical property and conditions of sintering.

This work was undertaken to investigate how electrical conduction in sintered bodies of calcium fluoride is influenced by a slight amount of water adsorbed on the surfaces of the starting powders. Powders of calcium fluoride by the recrystallization process through fluoric acid contain a slight amount of water ${ }^{6)}$. The bulk (crystal lattice) conduction and the extrinsic conduction were also investigated with respect to fluorine vacancy formation by the inclusion of water in the starting powder.

\section{Experimental and Results}

Calcium fluoride powders $(99.99 \%$ purity, grain size $0.1 \mu$ ) were pressed to pellets under a hydraulic pressure of about $1 \sim 2 \mathrm{~kg} / \mathrm{cm}^{2}$ and sintered under various conditions. The impurity components in the powders were $\mathrm{Fe}^{3+}, 0.001 \% ; \mathrm{Pb}^{2+}$ trace, $\mathrm{Al}^{3+}, 0.001 \%$; and $\mathrm{Si}^{4+}, 0.005 \%$.

Specimens with various degrees of sintering and sintering conditions are shown in Table 1 , 
Table 1. Sintering conditions and degrees of sintering.

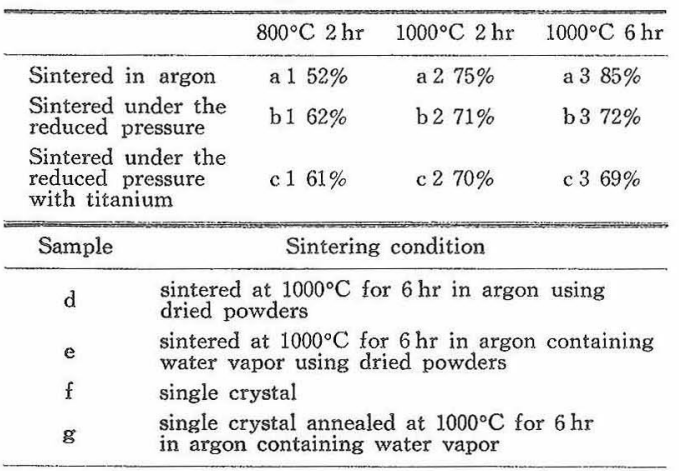

where degrees of sintering are given by the ratio of apparent density to theoretical density.

The samples a 1, a 2 and a 3 were sintered in an inert atmosphere of argon to prevent specimen. oxidation. The samples $\mathrm{b} 1, \mathrm{~b} 2$ and $\mathrm{b} 3$ were sintered under a reduced pressure of $1.5 \mathrm{mmHg}$ by vacuum pumping to eliminate water vapor from the calcium fluoride pellets.

The samples c1, c 2 and c 3 were obtained under a pressure of $0.8 \mathrm{mmHg}$, using spongy titanium as a getter to prevent pellet oxidation and gas adsorption as far as possible.

Even a trace (less than $1.0 \mathrm{ppm}$ ) of titanium in the pellets was not detected by the method of the solid state mass-spectroscopy.

Following procedure was adopted in order to examine the effect of water on ionic conductivity still more clearly. Starting powders of $\mathrm{CaF}_{2}$ were dried at about $200^{\circ} \mathrm{C}$ in air for $3 \sim 4$ hours. The amount of water adsorbed in the starting powders was measured as about $5 \times 10^{-2}$ mole fraction by Karl Fischer titration. After drying it decreased to $5 \times 10^{-3}$ mole fraction.

From these dried powders, sample $d$ was sintered at $1000^{\circ} \mathrm{C}$ for $6 \mathrm{hr}$ in dry argon, while sample e was sintered at $1000^{\circ} \mathrm{C}$ for $6 \mathrm{hr}$ in argon gas containing water vapor $(20 \mathrm{mmHg}$ ).

Single crystals $f$ and $g$ were purchased from Oyokolsen Company. Single crystal g was annealed at $1000^{\circ} \mathrm{C}$ for $6 \mathrm{hr}$ in argon containing water vapor $(300 \mathrm{mmHg})$. The photographs of scanning electron microscope are shown in Figs. 2, 3, 4 and 5.

Electrical conductivity measurements were made by a three electrode method on an alternating current bridge (ANDO-DENKI, LCR-6). Frequency dependency of conductivity was observed by an alternating current impedance bridge (ANDO-DENKI, DRZ-2M). Since contribution of capacitance was almost zero at $1 \mathrm{kHz}$, the values at $1 \mathrm{kHz}$ were adopted in the present work. Measurements were made in argon in the temperature range $700^{\circ} \mathrm{C}$ to $300^{\circ} \mathrm{C}$ while decreas.

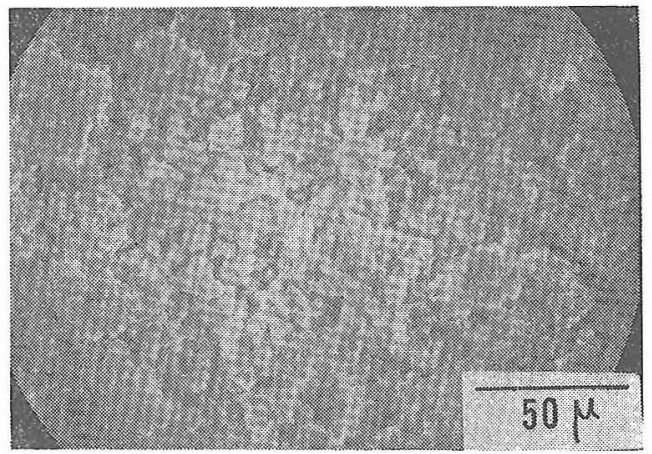

Fig. 2. Sample a $1\left(800^{\circ} \mathrm{C}, 2 \mathrm{hr}\right.$ sintered in argon $)$.

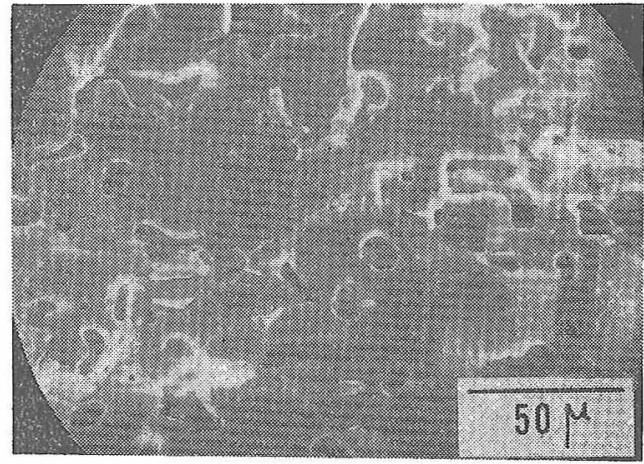

Fig. 3. Sample a $3\left(1000^{\circ} \mathrm{C}, 6 \mathrm{hr}\right.$ sintered in argon).

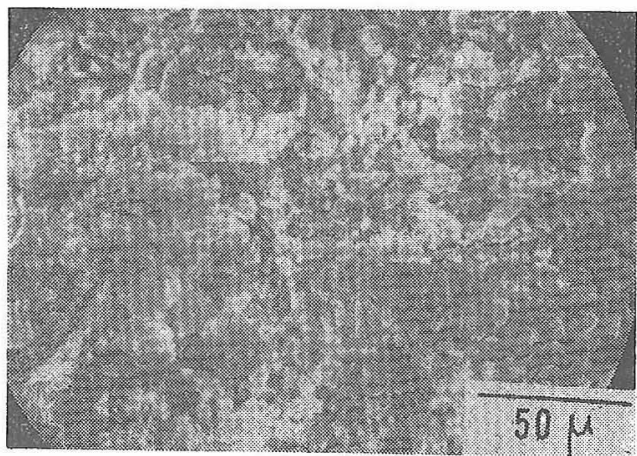

Fig. 4. Sample c $1\left(800^{\circ} \mathrm{C}, 2 \mathrm{hr}\right.$ sintered under the reduced pressure with titanium).

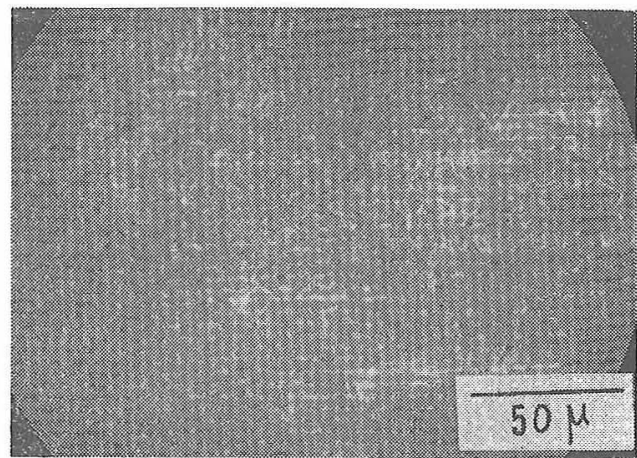

Fig. 5. Sample c $3\left(1000^{\circ} \mathrm{C}, 6 \mathrm{hr}\right.$ sintered under the reduced pressure with titanium). 
ing the temperature at the rate of $1 \mathrm{deg} / \mathrm{min}$.

Electrodes were made by firing silver paste (Dupont No. 4817) at $700^{\circ} \mathrm{C}$. Reproducible conductivity data, within a variation of $20 \%$ at the utmost, were obtained in repeated runs and little hysteresis effect was found within cycles of in-

(a)



Fig. 6. (a) degree of sintering and (b) ionic conductivity at $727^{\circ} \mathrm{C}$ vs. sintering condition

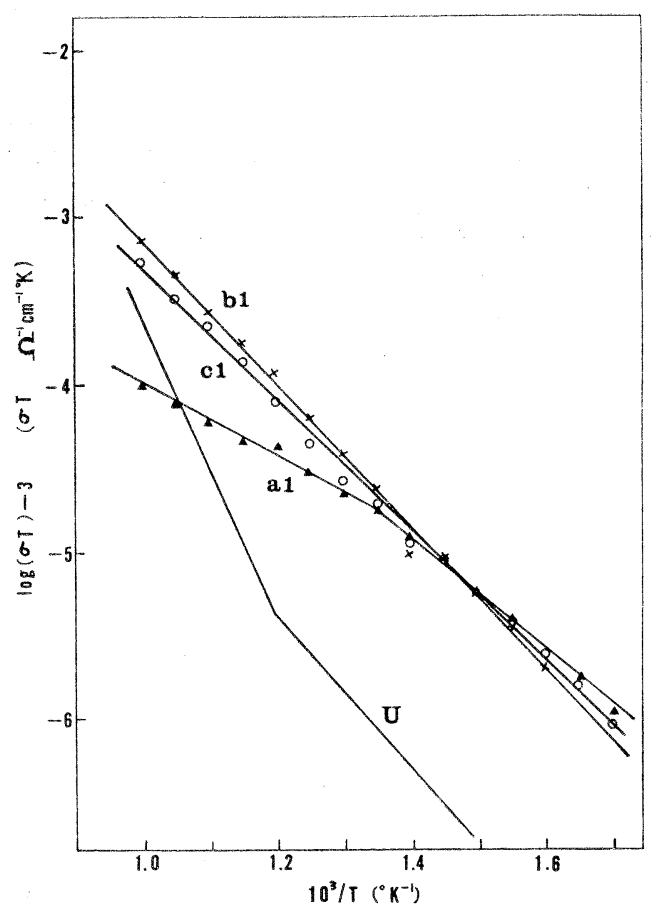

Fig. 7. $\log \sigma T^{r}$ vs. $1 / T$ in the samples a $1, b 1$ and $c 1$. creasing and decreasing temperature. Temperature was measured with chromel-alumel thermocouples. The relation among the extent of sintering, ionic conductivity at $727^{\circ} \mathrm{C}$ and the sintering condition was given in Fig. 6 (a), (b).

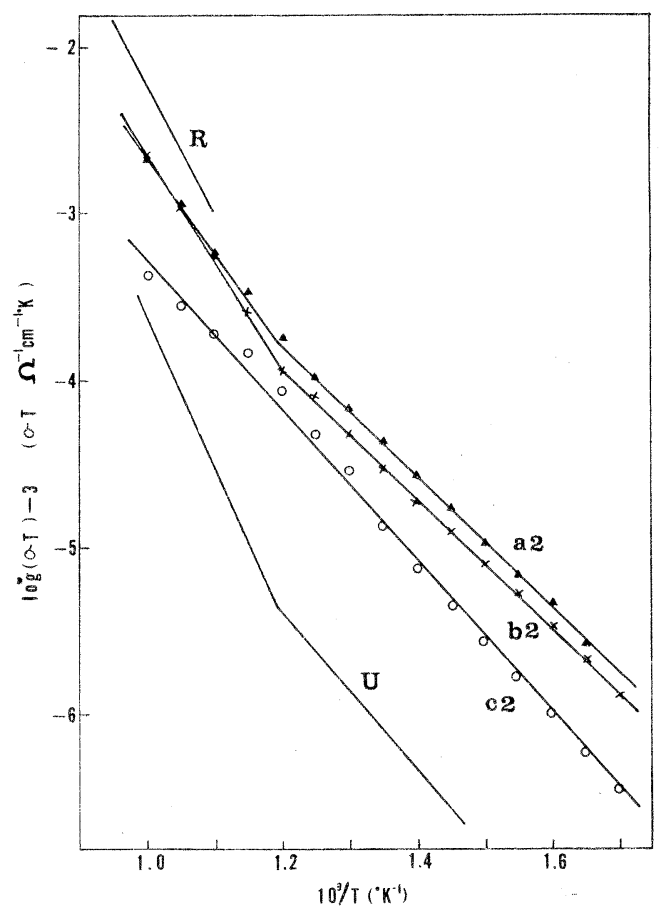

Fig. 8. $\log \sigma T$ vs. $1 / T$ in the samples a $2, \mathrm{~b} 2$ and $\mathrm{c} 2$.

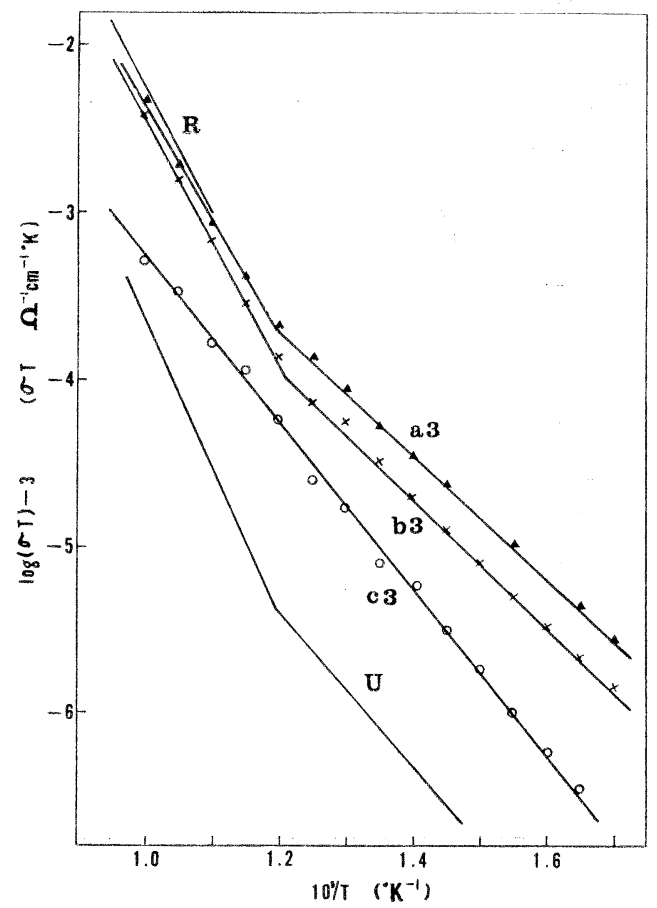

Fig. 9. $\log \sigma T$ vs. $1 / T$ in the samples a $3, \mathrm{~b} 3$ and $\mathrm{c} 3$, 
Conductivities are shown in Figs. 7, 8, 9, 10 and 11 plotting $\log \sigma T$ vs. $1 / T$; values for single crystal $\mathrm{CaF}_{2}$ measured by $\mathrm{Ure}^{1)}$ are also given for reference. Activation energies calculated from the slopes are listed in Table 2; a value for oxygen doped single crystal obtained by Rossing ${ }^{7}$ is also given. The amount of water adsorbed in sample a $1\left(800^{\circ} \mathrm{C}, 2 \mathrm{hr}\right.$ in argon) was measured as about $7.2 \times 10^{-3} \mathrm{~mol}$ fraction by a vacuum fusion method $^{8)}$. This is far larger than the amount of impurties in the starting powders $\left(1.0 \times 10^{-4}\right.$ mol fraction). The effect of impurities on the ionic conductivity of such a specimen is negli-

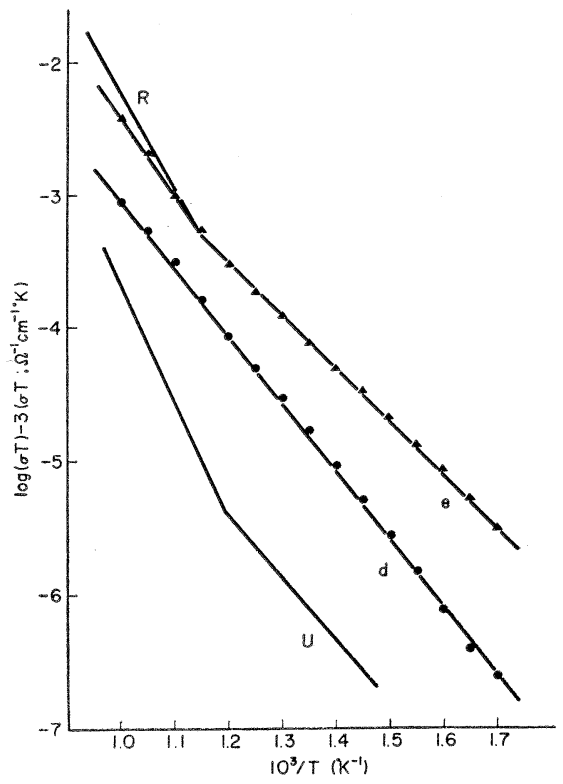

Fig. 10. $\log \sigma T$ vs. $1 / T$ in the samples $d$ and e.

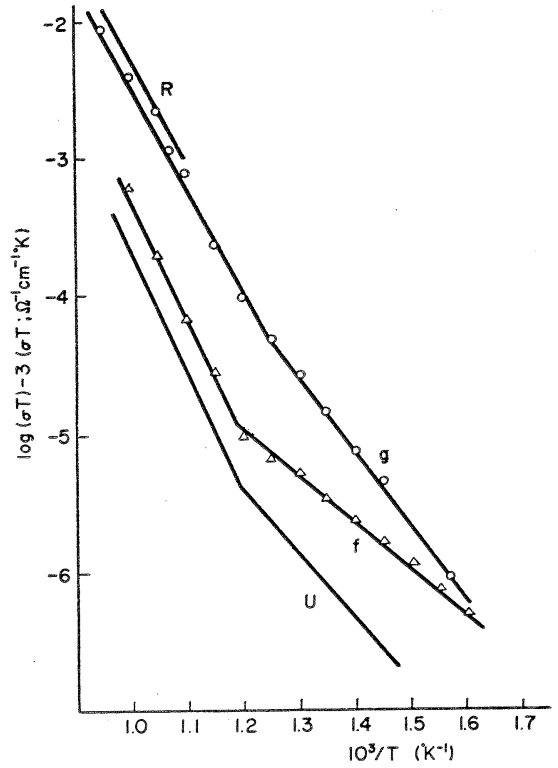

Fig. 11. $\log \sigma T$ vs. $1 / T$ in the samples $\mathrm{f}$ and $\mathrm{g}$.
Table 2. Activation energies against ionic conduction in the samples with various grades of sintering.

\begin{tabular}{ccc}
\hline Samples & $\begin{array}{c}\text { High temperature } \\
\text { region (eV) }\end{array}$ & $\begin{array}{c}\text { Low temperature } \\
\text { region }(\mathrm{eV})\end{array}$ \\
\hline a 1 & $0.45 \pm 0.03$ & $0.70 \pm 0.05$ \\
b 1 & $0.81 \pm 0.05$ & $0.81 \pm 0.05$ \\
c 1 & $0.76 \pm 0.05$ & $0.76 \pm 0.05$ \\
a 2 & $1.18 \pm 0.10$ & $0.78 \pm 0.05$ \\
b 2 & $1.23 \pm 0.10$ & $0.75 \pm 0.05$ \\
c 2 & $0.90 \pm 0.05$ & $0.90 \pm 0.05$ \\
a 3 & $1.27 \pm 0.10$ & $0.72 \pm 0.05$ \\
b 3 & $1.43 \pm 0.10$ & $0.75 \pm 0.05$ \\
c 3 & $0.99 \pm 0.05$ & $0.99 \pm 0.05$ \\
S.C. & $1.65 \sim 2.00$ & $0.75 \sim 1.00$ \\
S.C. (oxygen doped) 1.34 & \\
\hline
\end{tabular}

gible, if compared with the effect of water contamination.

\section{Discussions}

\subsection{Effect of water on the extent of sintering}

For the specimens sintered at $800^{\circ} \mathrm{C}$ for $2 \mathrm{hr}$ the extent of sintering was increased by lowering pressure as shown in Fig. 6(a) (compare b $1, \mathrm{c} 1$ and a 1). On the other hand, for the specimens sintered at $1000^{\circ} \mathrm{C}$ for $6 \mathrm{hr}$, the effect of lowering pressure and of eliminating water from atmosphere was to decrease the degree of sintering (compare b 3, c 3 and a 3 ). A significant increase in the extent of sintering with time and temperature was observed for samples sintered in the argon atmosphere, for which precautions to eliminate water vapor had not been taken (a 1, a 2 and a 3 ). The degree of sintering, however, hardly changed in samples c $1, \mathrm{c} 2$ and $\mathrm{c} 3$, where precautions had been taken to eliminate water from specimens. The photograph of a 3 shows a growth of closed pores in Fig. 3. Thus, water increased the extent of sintering at $1000^{\circ} \mathrm{C} 6 \mathrm{hr}$, while decreased it at $800^{\circ} \mathrm{C} 2 \mathrm{hr}$.

\subsection{Effect of water on the conductivity of the specimens sintered at $800^{\circ} \mathrm{C} 2 \mathrm{hr}$ (a $1, \mathrm{~b} 1, \mathrm{c} 1$ )}

Effect of lowering pressure is remarkably observed on the conductivities of $\mathrm{a} 1, \mathrm{~b} 1$ and $\mathrm{c} 1$ in Fig. 6(b).

In Fig. 7, the plots for samples b 1 and c 1 show straight lines. One may easily notice that these two lines are approximately parallel to the line for the single crystal in the low temperature region. The activation energies calculated from the slopes for samples b $1(0.81 \mathrm{eV})$ and $\mathrm{c} 1(0.76$ $\mathrm{eV})$ are close to those for migration of fluorine ions $(0.75 \sim 1.10 \mathrm{eV})^{1) \sim 5}$ observed in single crystals. Thus, conduction in samples b 1 and c 1 involves only migration of fluorine ions as an extrinsic conduction (grain boundary conduction 
of impurity enhanced conduction).

On the other hand, in specimen a 1 the activation energy in the high temperature region $(0.45$ $\mathrm{eV})$ is smaller than that in the low temperature region $(0.70 \mathrm{eV})$. These differences between a 1 and b1, c 1 should come from the sintering atmosphere. Since the activation energy of a $1(0.45$ $\mathrm{eV}$ ) is very small, it is not so unreasonable to consider that the low value is due to a migration of fluorine ions along inner surfaces of the sintered bodies. The original surface of the starting powders was partly kept as open pores in the porous sample a 1 . As a result, the conduction along the inner surface would appear in the sample a 1. Discussions in detail on this point were given elsewhere ${ }^{9}$.

3.3 Effect of water on the conductivity of the specimens sintered at $1000^{\circ} \mathrm{C} 2 \mathrm{hr}$ and $1000^{\circ} \mathrm{C} 6 \mathrm{hr}$ (a 2, a 3, b 2, b 3, c 2 and c 3)

In Figs. 8 and 9 the conductivity of a $2, \mathrm{a} 3, \mathrm{~b}$ 2 and b 3 are one or two orders of magnitudes larger than those of $\mathrm{c} 2$ and $\mathrm{c} 3$. These differences result from the difference in the atmosphere during sintering. The samples a 2 and a 3 were sintered under an atmosphere containing water vapor, while c 2 and c 3 were sintered under conditions free from gases. The conduction of b 3 and a 3 in the high temperature region is explained as follows.

Rossing ${ }^{\text {7) has }}$ reported that oxygen is soluble in calcium fluoride up to $0.08 \%\left(640^{\circ} \mathrm{C}\right), 0.16 \%$ $\left(675^{\circ} \mathrm{C}\right)$ and $0.30 \%\left(730^{\circ} \mathrm{C}\right)$. Calcium oxide forms a solid solution with calcium fluoride, giving rise to fluorine vacancies, which are generated by incorporating oxygen ions in fluorine ion sites as

$$
2 \mathrm{FF}^{\times}+\mathrm{H}_{2} \mathrm{O}(\mathrm{g}) \rightarrow \mathrm{VF}^{\cdot}+\mathrm{O}^{\prime}+2 \mathrm{HF}(\mathrm{g}),
$$

where Kroeger and Vink's notations for lattice defects are used ${ }^{10)}$. Calcium oxide is easily segregated as

$$
\mathrm{Ca}_{\mathrm{Ca}}{ }^{x}+\mathrm{O}_{\mathrm{F}}{ }^{\prime}+\mathrm{V}_{\mathrm{F}}{ }^{\cdot} \rightarrow \mathrm{CaO}(\mathrm{s})
$$

if the concentration of oxygen exceeds the solubility limit. Rossing further reported that the conductivity of oxygen doped single crystal is dependent on the concentration of fluorine vacancies produced by incorporating oxygen. The line (R) in Fig. 9 is the ionic conductivity of $\mathrm{CaF}_{2}$ single crystal doped with saturated amount of oxygen, where the concentration of oxygen incorporated in $\mathrm{CaF}_{2}$ crystal is just the solubility limit at corresponding temperature. The segregation of calcium oxide takes place as temperature is lowered. The conductivity and the activation energy in the high temperature region observed for sample a 3 are almost the same as the values observed for the single crystal containing oxygen ions by the solubility limit, as shown in Fig. 9.
The ionic conduction in this case would be bulk migration of fluorine vacancies produced by incorporating water into the crystal lattice during sintering.

The effect of water on ionic conductivity can also be confirmed by the results in Figs. 10 and 11. In Fig, 10 the conductivity of sample $d$ (dried powders, dry argon) is the same as that of sample c 3 (wet powders, dewatered atmosphere). The conductivity of sample e (dried powders, wet argon) is the same as the values for sample a 3 (wet powders, dried argon) and single crystal $\mathrm{R}\left(\mathrm{O}^{2-}\right.$ doped).

In Fig. 11 the conductivity of single crystal $\mathrm{g}$ (annealed in wet argon) is the same as that of single crystal $\mathrm{R}\left(\mathrm{O}^{2-}\right.$ doped).

Therefore the ionic conduction a 3 is considered to be of bulk type due to migration of fluorine vacancies produced by incorporating oxygen from water into crystal lattice.

The amount of water adsorbed in $\mathrm{CaF}_{2}$ crystal a $1(0.72 \mathrm{~mol} \%)$ was sufficiently larger than the solubility limit $\left(0.30 \mathrm{~mol} \%\right.$ at $\left.730^{\circ} \mathrm{C}\right)$ and the diffusion depth of oxygen in calcium fluoride (1.0 $\mathrm{mm}$ at $1000^{\circ} \mathrm{C} 6 \mathrm{hr}$ ) by Phillips ${ }^{11)}$ is large enough for oxygen ions to penetrate into the grain of $\mathrm{CaF}_{2}(0.1 \mu)$.

The activation energies in samples c $2(0.90 \mathrm{eV})$ and $\mathrm{c} 3(0.99 \mathrm{eV})$ and those in the low temperature region for a $2(0.78 \mathrm{eV})$, a $3(0.72 \mathrm{eV})$, b 2 $(0.75 \mathrm{eV})$ and $\mathrm{b} 3(0.75 \mathrm{eV})$ are almost the same as those observed at low temperatures in $\mathrm{CaF}_{2}$ single crystals $(0.75 \sim 1.10 \mathrm{eV})^{1) \sim 5)}$. These conductions due to migrations of fluorine ions are considered to be grain boundary conduction or impurity enhanced conduction as an extrinsic mechanism. It is most possibly postulated that grain boundaries are far more contaminatedby water or oxygen in the samples a 2 , a 3, b 2 and b 3 than in those $c 2$ and c 3 . This may be the reason for the fact that the extrinsic conductivities in the samples a 2, a 3, b 2 and b 3 are greater than those in the samples $\mathrm{c} 2$ and $\mathrm{c} 3$.

\section{Conclusion}

(1) Effects of water upon sintering of $\mathrm{CaF}_{2}$ powders and ionic conductivity of sintered $\mathrm{CaF}_{2}$ were investigated.

(2) Water depressed the extent of sintering in the primary stage of sintering while increased it in the final stage of sintering.

(3) Ionic conductivity of $\mathrm{CaF}_{2}$ sintered from $\mathrm{CaF}_{2}$ powders containing water was far larger than that containing no water. Water produced fluorine vacancies by incorporating oxygen atoms into the crystal lattice. 


\section{Acknowledgement}

The present authors express their thanks to Dr. K. Furuya for valuable discussion and giving us the data in the vacuum fusion method.

\section{References}

1) R.W. Ure, Jr., J. Chem. Phys. 26, 1363-73(1957).

2) T.I. Nikitinskaya, E.V. Suntsov and M.S. Tyutin, Fizika Tverdogo Tela 9 [7] 2111-13 (1967).

3) V.F. Pisarenko and V.V. Popov, Izv. Akad. Nauk. USSR, ser. Fiz, 31 [12] 2052-54 (1967).

4) V.A. Arkhangel'skaya, B.G. Mikheev, T.I. Nikitinskaya and M.S. Tyutin, Fizika Tverdogo Tela 9 [2] 687-89 (1967).
5) E. Barsis and A. Taylor, J. Chem. Phys. 45, 1154 $-62(1966)$.

6) R. Kiriyama, private communication.

7) B.R. Rossing, Ph.D. Thesis, M.I.T. (1966) p. 50-67.

8) G.G. Glavin, U.A. Karpov, B.A. Slzhataer, Zav. Lab. 35 [2] 172-75 (1969).

9) S. Mizuta, H. Yanagida, Japan J. Electrochem. Soc. 40 [11] 787-91 (1972).

10) F.A. Kroeger and H.J. Vink, "Solid State Physics" vol. 3, Ed. F. Seitz and D. Turnbull, Academic Press, New York (1956) p. 307.

11) W.L. Phillips, Jr. and J.E. Hanlon, J. Am. Ceram. Soc. 46, 447-49 (1963).

[Received April 20, 1973]

\title{
弗化カルシウム焼結体のイオン伝導度に及ぼす水分の影響
}

\author{
水田 進・新井精一・柳田博明 \\ (暂京大学 工学部 工業化学科)
}

\begin{abstract}
弗化カルシウムの焼結に扔いて, 原料粉末に吸着して いる水分の影響を調べた．単にアルゴン中で焼結した場 合と，水分を除去しつつ減圧下で燒結した場合とを比較 した.この結果, 水の存在は, 焼結組織掞よび燒結体の
\end{abstract} れた.酸素をドープした単結晶の伝導度との比較から， 水は弗化カルシウムと反応し, 弗素空孔を生じていると

(4/20/1973 受村)

結論された。 